\title{
The effects of dietary lipids on adrenergically-stimulated lipolysis in perinodal adipose tissue following prolonged activation of a single lymph node
}

\author{
Christine A. Mattacks, Dawn Sadler and Caroline M. Pond* \\ Department of Biological Sciences, The Open University, Milton Keynes, Bucks. MK7 6AA, UK \\ (Received 22 August 2001 - Revised 26 November 2001 - Accepted 21 December 2001)
}

\begin{abstract}
The effects of feeding beef suet (mostly saturated and monoenoic fatty acids), sunflower oil (rich in $n-6$ fatty acids) and fish oil (rich in $n-3$ fatty acids) on the response of mesenteric, omental, popliteal and perirenal adipocytes to experimentally-induced local inflammation were studied in adult guinea pigs. After 6 weeks on the experimental diets, the animals were fed standard chow, and lipopolysaccharide was injected unilaterally daily for $4 \mathrm{~d}$ to induce swelling of one popliteal lymph node. Basal lipolysis in the perinodal adipocytes of all depots studied was higher in the sunflower oil-fed animals than in the controls fed on standard chow, and lower in those fed on suet or fish oil. Dietary lipids altered rates of lipolysis during incubation with $10^{-5} \mathrm{M}$ noradrenaline in all samples studied from the locally-activated popliteal depot, but only in adipocytes within $5 \mathrm{~mm}$ of a large lymph node in the other depots. The fish-oil diet attenuated the spread of increased lipolysis within the locally-activated popliteal adipose tissue, and from this depot to other node-containing depots. These experiments show that $n-6$ polyunsaturated fatty acids promote and $n-3$ fatty acids suppress the spread of immune activation to adipocytes within and between depots, and alter the sensitivity of perinodal adipocytes to noradrenaline. Dietary effects are reduced or absent in adipocytes in sites remote from lymph nodes, and thus such samples do not adequately represent processes in perinodal adipose tissue. These results are consistent with the hypothesis that perinodal adipocytes interact with adjacent lymphoid cells during immune responses.
\end{abstract}

Site-specific properties: Fish oil: $n$-6 Polyunsaturated fatty acids: Local interactions: Guinea pig

Long-chain fatty acids are major metabolic fuels, as well as components of cell membranes and precursors of signal molecules secreted by immune cells. Fatty acids of particular chain length and unsaturation are much more efficient in the latter roles than others, and only minor intracellular modification is possible. Consequently, the lipid composition of the diet can alter many aspects of immune function (Calder, 2001). Most experimental investigations relate the current or very recent diet to immune processes, and assume that lymphoid cells acquire lipids directly from the blood or lymph, in competition with other tissues (Sanderson et al. 1995; Sadeghi et al. 1999; Wallace et al. 2001). Hypotheses concentrate on lipid metabolism in the immune cells themselves (Hwang, 2000). Anorexia is often associated with substantial or prolonged immune activation (Langhans, 2000), so stored nutrients may be as important as the current diet in determining the contribution of nutrition to the course of inflammatory diseases (Grimble, 1998).

Adipocytes are now known to secrete and respond to many cytokines that were first described in the immune system (Coppack, 2001). Several cytokines stimulate the release of fatty acids and/or glutamine from adipocytes in vitro, but exactly where and how adipose tissue in vivo makes these essential nutrients available to lymphoid cells during periods of anorexia or malnutrition, or even normal metabolism, have been little explored. The sitespecific properties of the adipocytes surrounding lymph nodes (perinodal adipose tissue) are consistent with the hypothesis that they are specialized to provision and regulate adjacent lymphoid cells (Pond, 1999, 2001). In certain depots, including the popliteal (POP), repeated immune stimuli induce properties characteristic of the perinodal adipocytes in adipocytes at least $10 \mathrm{~mm}$ distant from a 
major lymph node in guinea pigs (Pond \& Mattacks, 2002). The triacylglycerols of perinodal adipocytes of all major node-containing depots contain proportionately more polyunsaturated fatty acids than those remote from lymph nodes and from nodeless depots (Mattacks \& Pond, 1997). Adipose tissue explants from guinea pigs that were fed on suet-enriched chow for three months, interact much less strongly with lymphoid cells when co-incubated in vitro for $48 \mathrm{~h}$ than similar tissues from animals fed on standard chow. The manifestation of receptors to tumour necrosis factor $\alpha$ on the surface of perinodal adipocytes in the hours after a simulated immune challenge is also reduced in rats that were fed suet-enriched chow (MacQueen et al. 2000). These experiments indicate that reception and/or secretion of cytokines that mediate local interactions between adipose and lymphoid cells are modulated by the fatty acid composition of the recent diet.

The ultrastructure of the sympathetic innervation of adipocytes has been studied in detail (Cinti, 2001), but little is known about site-specific differences in neural control within or between depots. Although perinodal adipocytes apparently contribute little to the whole-body energy supply during fasting, they respond readily to catecholamines in vitro, reaching rates of lipolysis up to $20 \%$ higher than adipocytes from nodeless depots of the same animals (Mattacks \& Pond, 1999). As well as regulating lipolysis and the secretion of several cytokines including tumour necrosis factor $\alpha$ and interleukin 6 from adipocytes (Rayner, 2001), noradrenaline is also known to act on lymphoid cells, including spleen lymphocytes (Rogausch et al. 1999) and dendritic cells (Maestroni, 2000). Activation of immune cells is mediated primarily by cytokines, but there is also evidence for the involvement of the adrenergic system. Immune stimulants such as lipopolysaccharide (LPS) can alter the expression of $\beta_{3}$-adrenergic receptor mRNA in large murine adipose depots (Berkowitz et al. 1998), but no effects on sensitivity to catecholamines have been demonstrated. Metabolic regulators of adrenergic stimulation of lipolysis have been extensively studied and various agents have been identified (Björntorp, 1996; El Hadri et al. 1997; Orban et al. 1999), but dietary lipids were not thought to be among them: Mersmann et al. $(1992,1995)$ found only minimal effects of dietary fats on the abundance or functioning of adrenergic receptors in pig adipocytes, although their experimental diets induced marked differences in the fatty acid compositions of the adipocyte membranes. However, these studies were limited to adipocytes from subcutaneous or large intra-abdominal depots that are not associated with lymphoid tissue.

In the present study, we explore the contribution of lipids previously sequestered from the diet in storage tissues to immune-stimulated and catecholamine-mediated interactions between lymphoid and adipose tissues following experimentally-induced local inflammation.

\section{Methods}

\section{Animals}

Bolivian guinea pigs were bred and raised at the Open University (Milton Keynes, Bucks., UK) in standard cages $\left(\right.$ area $0.45 \mathrm{~m}^{2}$ ), at a room temperature of $22-23^{\circ} \mathrm{C}$, and were transferred to permanent groups at weaning. They were fed on breeding-grade guinea-pig chow (FD1; Special Diet Services, Witham, UK), which contained $34 \mathrm{~g}$ crude lipid $/ \mathrm{kg}$, available ad libitum, plus hay every day, and cabbage, carrot and apple on $5 \mathrm{~d} /$ week. Water with added vitamin C $(0 \cdot 1 \mathrm{mg} / \mathrm{ml})$ was available ad libitum. Guinea pigs were rejected if they had visible local or systemic infections, imperfect coat or skin, or showed signs of severe stress.

At the age of 8-12 months (i.e. when fully mature), groups of nine or ten (six females + three or four males) were placed on lipid-enriched chow (the controls continued on the standard FD1 chow). The supplemented chows were made by crushing the FD1 chow pellets and reconstituting them with $100 \mathrm{~g}$ either shredded beef suet (Tesco's or Atora brand), sunflower oil (Tesco's or Flora brand) or fish oil (donated by Seven Seas Ltd, Hull, UK)/kg, which increased the lipid content of the chow to about $130 \mathrm{~g} / \mathrm{kg}$. The proportions of the major classes of fatty acids in the resulting mixtures are listed in Table 1.The lipid-enriched chows were freshly prepared twice per week, and after drying to a firm consistency for $2 \mathrm{~d}$ in air were eaten within $3 \mathrm{~d}$. Any mixture that smelt strongly was discarded at once.

All the animals readily ate the modified chows, and there was no evidence that it was distasteful to them.

Table 1. Summary of the proportions ( $\mathrm{g} / 100 \mathrm{~g}$ total fatty acids extracted) of saturated monoenoic, $n-6$ polyunsaturated and $n-3$ polyunsaturated fatty acids in the triacylglycerols extracted from standard chow ( $34 \mathrm{~g}$ digestible fat $/ \mathrm{kg}$ ) and supplemented chows $(134 \mathrm{~g} \text { digestible fat } / \mathrm{kg})^{*}$

\begin{tabular}{|c|c|c|c|c|c|}
\hline Diet & Saturated $\dagger$ & Monoenoicł & $n-6$ PUFA§ & $n$-3 PUFA\|l & Unsaturation index \\
\hline andard chow & $36 \cdot 4$ & 33.9 & $24 \cdot 3$ & 5.4 & 107 \\
\hline Chow +b & 4 & & & 7.7 & 71 \\
\hline how+sunflower oil & & & & & \\
\hline how+fish oil & - & & & $11 \cdot 6$ & \\
\hline \multicolumn{6}{|c|}{ 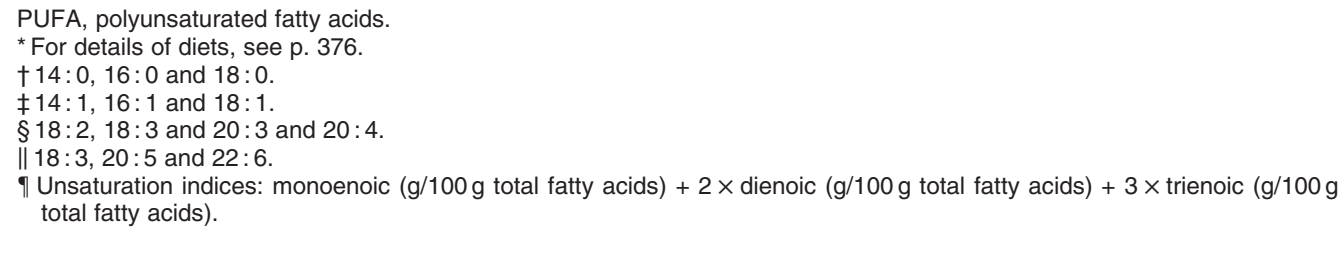 } \\
\hline
\end{tabular}


The animals remained on this diet for 6 weeks and were switched back to the unmodified, standard chow for the last $4 \mathrm{~d}$ before killing, during which time local inflammation was induced by daily injections of LPS. LPS dissolved in sterile $25 \mathrm{~mm}-\mathrm{PBS}$ at $\mathrm{pH} 7.4$ was injected subcutaneously (20 $\mu \mathrm{g}$ LPS/kg body mass) into the left lower leg about $8 \mathrm{~mm}$ cranial to the calcaneus, i.e. into the region of the skin drained by the left POP lymph node. Each animal was isolated, with food and water available, for $18 \mathrm{~h}$ before being killed at about 09.30 hours on the fifth day with minimal stress and excitement by means of an intraperitoneal injection of pentabarbitone.

\section{Tissue samples}

The dissection was begun at once and completed within $30 \mathrm{~min}$, following the protocol described previously (Mattacks \& Pond, 1997; Pond \& Mattacks, 2002) that distinguishes between perinodal adipose tissue from within $2 \mathrm{~mm}$ of a lymph node, 'remote' samples taken from about $10 \mathrm{~mm}$ away from any lymph nodes and 'middle' samples taken from about half-way between these sites about $5 \mathrm{~mm}$ from a lymph node. Such triplets of samples were collected from the stimulated (left) and unstimulated (right) POP depots separately. Perinodal and remote samples were also obtained from the mesentery and the equivalent material from the omentum: the slightly darker region in which assemblages of lymphoid cells form numerous 'milky spots' that are functionally similar to lymph nodes (Shimotsuma et al. 1993), and the paler region that has few milky spots. The sample sites were selected by an experienced operator (CAM) entirely on the basis of the adipose tissue's anatomical relations to lymph nodes. A sample was also taken from the perirenal depot, which in guinea pigs does not contain any lymph nodes. The single left and right POP lymph nodes, and four large conspicuous mesenteric nodes were also dissected out and weighed.

\section{Measurement of lipolysis}

To isolate the adipocytes, each sample was cut into 1$2 \mathrm{~mm}$ fragments that were incubated at $37^{\circ} \mathrm{C}$ for up to $1 \mathrm{~h}$ in $10 \mathrm{ml}$ Krebs buffer+bovine serum albumin $(20 \mathrm{~g} / \mathrm{l})$ at
$\mathrm{pH} 7.4$ and collagenase $(1 \mathrm{mg} / \mathrm{ml})$ in a gently shaking water-bath. Tissue debris was removed using a widemesh cell strainer. Adipocytes were collected on a $70 \mu \mathrm{m}$ cell strainer and re-suspended and washed three times in $10 \mathrm{ml}$ Hanks' balanced salt solution. The suspensions were allowed to stand for $10 \mathrm{~min}$ while adipocytes floated to the surface where they were removed with a pipette and re-suspended by gentle shaking in $1 \mathrm{ml}$ Hanks' balanced salt solution. Three $10 \mu \mathrm{l}$ samples of each suspension were removed for inspection and counting of adipocytes in a haemocytometer. The average of three estimations of cell number for each adipose tissue sample was used.

Basal and noradrenaline (NOR)-stimulated lipolysis was measured within $4 \mathrm{~h}$ of excision in duplicate $10 \mu \mathrm{l}$ aliquots of each sample of adipocytes, diluted if necessary to produce approximately 2000 cells $/ 20 \mu \mathrm{l}$ well. The free glycerol released was assayed using the glycerol kinase method described in detail by Pond \& Mattacks (1995, 1998). The numbers of adipocytes/ml to the nearest 100 cells was measured with a haemocytometer. These values were used to normalize the glycerol measurements, thus improving precision and reproducibility by correcting for minor differences in adipocyte concentration.

Data were analysed using the Statistical Package for Social Sciences (SPSS Inc., Chicago, IL, USA). $P$ values refer to Fisher's $F$ test or to Student's two-sided $t$ test, with $P<0.05$ being taken as significant.

\section{Results}

\section{Structural results}

Table 2 lists the morphological results obtained at dissection. The final body masses of the guinea pigs were not significantly altered by the experimental diets (ANOVA by diet: $F 0.71$, NS). The locally stimulated (left) lymph node and the conspicuous mesenteric lymph nodes were similar in mass under all the regimens (ANOVA by diet: left POP $F 0 \cdot 20$, mesenteric $F 0 \cdot 512$; NS). The masses of the right (non-stimulated) POP lymph node differed between experimental groups $(F 10 \cdot 83, P<0 \cdot 001)$, being larger in guinea pigs fed on either the sunflower oil or the fish oil, though always much smaller than the homologous node that drained the skin that had been injected with LPS (Table 2). As we have found previously (Pond

Table 2. Effect of dietary lipids on body masses $(\mathrm{g})$ and masses (mg) of the lipopolysaccharide-stimulated (left) and the unstimulated (right) popliteal lymph nodes, and the average of a sample of four mesenteric lymph nodes from each specimen of the four dietary groups $\dagger$

(Mean values with their standard errors)

\begin{tabular}{|c|c|c|c|c|c|c|c|c|c|c|c|c|c|}
\hline \multirow[b]{3}{*}{ Diet } & \multirow[b]{3}{*}{$n$} & \multirow{2}{*}{\multicolumn{2}{|c|}{$\begin{array}{l}\text { Body mass } \\
\text { (g) }\end{array}$}} & \multicolumn{6}{|c|}{ Popliteal lymph node (mg) } & \multirow{2}{*}{\multicolumn{2}{|c|}{$\begin{array}{l}\text { Mesenteric } \\
\text { lymph node } \\
(\mathrm{mg})\end{array}$}} & \multirow{2}{*}{\multicolumn{2}{|c|}{$\begin{array}{l}\text { Stimulated } \\
\text { popliteal } \\
\text { nodes:mesen- } \\
\text { teric nodes }\end{array}$}} \\
\hline & & & & \multicolumn{2}{|c|}{ Stimulated } & \multicolumn{2}{|c|}{ Unstimulated } & \multicolumn{2}{|c|}{$\begin{array}{l}\text { Stimulated: } \\
\text { unstimulated }\end{array}$} & & & & \\
\hline & & Mean & SE & Mean & SE & Mean & SE & Mean & SE & Mean & SE & Mean & SE \\
\hline Standard chow & 9 & 886 & 75 & $14 \cdot 1$ & $1 \cdot 37$ & 1.9 & 0.13 & $7 \cdot 81$ & 0.90 & $4 \cdot 29$ & 0.85 & 3.33 & 0.09 \\
\hline Chow+beef suet & 10 & 1008 & 44 & $12 \cdot 8$ & 0.53 & $2 \cdot 3$ & 0.15 & $5 \cdot 80$ & 0.46 & $3 \cdot 31$ & 0.25 & $4 \cdot 15$ & 0.46 \\
\hline Chow+sunflower oil & 9 & 992 & 66 & $14 \cdot 8$ & 0.72 & $3 \cdot 1^{*}$ & 0.26 & $5 \cdot 10$ & 0.56 & $3 \cdot 69$ & 0.27 & $4 \cdot 26$ & 0.46 \\
\hline Chow+fish oil & 10 & 964 & 66 & $15 \cdot 5$ & 0.79 & $3 \cdot 1^{*}$ & 0.18 & $5 \cdot 17$ & 0.45 & 3.72 & 0.21 & $4 \cdot 22$ & 0.25 \\
\hline
\end{tabular}

* Mean values are significantly different from the standard chow regimen $P<0.05$.

†For details of diets and procedures, see Table 1 and p. 376. 
\& Mattacks, 1998, 2002; Mattacks \& Pond, 1999), the adipocyte isolation procedure yielded 1600-2100 intact cells/ml, with the perinodal samples, especially those from POP, consistently producing more adipocytes than others.

\section{Site-specific differences in rates of glycerol release}

Rates of glycerol release from the eleven samples of adipocytes from the guinea pigs that ate standard chow throughout are shown in left columns of Table 3. As we have reported previously (Mattacks \& Pond, 1999), the $18 \mathrm{~h}$ fast produced similar rates of 'basal' lipolysis in the remote from node samples from the node-containing depots and the perirenal adipocytes. The application of NOR in vitro further raised the rate of glycerol release, and the maximum values in the presence of $10^{-5} \mathrm{M}-\mathrm{NOR}$ are highest in the mesentery and omentum, and lowest in the perirenal. Site-specific differences in the rates of lipolysis in the node-containing depots after $4 \mathrm{~d}$ of stimulation with LPS were similar to those that develop within the first $24 \mathrm{~h}$ of an immune response (Pond \& Mattacks, 2002). In the presence of NOR at the physiological range of concentrations $\left(10^{-7} \mathrm{M}\right)$, rates of lipolysis in all three samples of the stimulated POP were similar, but both basal and maximal lipolysis were higher in the perinodal than the remote samples $(t 2 \cdot 789, P<0 \cdot 05)$. Basal lipolysis from the perinodal samples was consistently higher than that from the remote samples of the same depot, with the middle sample similar to the perinodal in the stimulated POP depot but close to the values for the remote samples in the unstimulated leg. Rates of lipolysis in the mesenteric and omental perinodal samples were highly significantly higher $(P<0.001)$ than in the corresponding remote samples under all conditions studied except omental in the presence of $10^{-5} \mathrm{M}-\mathrm{NOR}$.

\section{The effects of dietary lipids on site-specific differences in rates of glycerol release}

Table 3 also shows measurements from the homologous samples from guinea pigs that had eaten the lipid-enriched diets. Basal lipolysis was significantly higher in the perinodal sample of the LPS-stimulated POP from the sunflower oil-fed animals compared with the controls ( $t$ 2.887, $P<0.02$ ), and lower in all samples from this depot from guinea pigs that ate fish oil $(t 3.491, P<0 \cdot 01)$. Feeding suet or fish oil also significantly depressed lipolysis in the remote adipocytes compared with the homologous samples from the controls or sunflower oil-fed animals. Lipolysis in the middle samples was not significantly different from that in the perinodal adipocytes, but significantly different from the remote sample, in all samples from the stimulated POP except those from fish oil-fed guinea pigs. ANOVA for the effects of diet (Table 4) reveals a highly significant effect of diet on all POP samples from the LPS-stimulated leg under all conditions studied. Lipolysis in the perinodal samples under maximal stimulation with $10^{-5} \mathrm{M}$-NOR was significantly higher for adipocytes from the guinea-pigs fed on standard chow or chow plus sunflower oil compared with adipocytes from elsewhere in the same depots and the homologous samples from suet or fish oil-fed animals. Values from adipocytes incubated with $10^{-7} \mathrm{M}-\mathrm{NOR}$ were intermediate, with those from the fish oil-fed guinea pigs significantly lower than those from the animals given sunflower oil or standard chow.

Corresponding measurements from adipocytes from the contralateral unstimulated POP depot present a qualitatively similar picture. Rates of lipolysis in the presence of $10^{-5} \mathrm{M}-\mathrm{NOR}$ were almost identical in the two POP depots from the same guinea pigs, but with the lower dose of NOR, and in its absence, lipolysis in the perinodal adipocytes was lower in the unstimulated POP depot, and values from the middle samples were closer to those from the remote samples. Basal lipolysis in the unstimulated POP perinodal adipocytes of fish oil-fed guinea pigs was significantly lower than that from the suet-fed animals, although the values from the homologous samples of the LPS-stimulated POP were indistinguishable. The effects of diet on adrenergic-stimulated lipolysis were smaller in the unstimulated POP depot than in the corresponding samples from that containing the LPS-stimulated node, and none of the differences between values from the remote samples were significant.

All values for rates of lipolysis from mesenteric perinodal adipocytes were significantly higher than those for the corresponding remote samples. Dietary lipids had only a weak effect on basal and sub-maximal lipolysis (Tables 3 and 4) in remote mesenteric adipocytes, and none at all on maximal lipolysis. However, sunflower oil in the diet raised lipolysis in perinodal mesenteric adipocytes under all conditions studied, and fish oil curtailed maximal lipolysis in the presence of $10^{-5} \mathrm{M}-\mathrm{NOR}$. Values from the omentum present a similar picture, except that the suetenriched diet appears to have a similar effect on maximal NOR-stimulated lipolysis in the 'around milky spot' samples as the fish-oil diet. The experimental diets induced minimal changes to basal and NOR-stimulated lipolysis in the omental adipocytes not associated with milky spots.

Administering LPS daily for $4 \mathrm{~d}$ induced a small increase in basal lipolysis and that with $10^{-7} \mathrm{M}-\mathrm{NOR}$ in the perirenal depot of guinea pigs that had eaten sunflower oil over that of the animals on the other diets, but in contrast to the perinodal adipocytes, their rates of maximum lipolysis were not altered by any of these diet (Table 4).

\section{Discussion}

\section{Animals and diets}

Our lipid-supplemented diets induce substantial changes to the fatty acid composition of adipose tissue triacylglycerols in guinea pigs within 6 weeks (Colby \& Pond, 1993), although they provide less lipid than those fed to mice by Wallace et al. (2000), or to rats by Sanderson et al. (1995) and Moussa et al. (2000), and more than those fed to weanling guinea pigs by Pöschl et al. (1999). In contrast to expectations from rat experiments (e.g. Harris et al. 1998), the final body masses of the guinea pigs fed on the enriched chows were not significantly different from those of the controls eating standard chow. In previous experiments (Colby \& Pond, 1993; Mattacks \& 
Table 3. Basal and noradrenaline (NOR)-stimulated glycerol release ( $\mu \mathrm{mol} / \mathrm{h}$ per 100 adipocytes) from eleven samples of adipose tissue: perinodal, $2 \mathrm{~mm}$ ('middle') and $5 \mathrm{~mm}$ ('remote') from the single popliteal lymph node of the stimulated (left) leg and unstimulated (right) leg, perinodal and $5 \mathrm{~mm}$ ('remote') from conspicuous mesenteric lymph nodes, from the region of the omentum rich in milky spots, or with few milky spots ('remote') and from the nodeless perirenal depotł

(Mean values with their standard errors)

\begin{tabular}{|c|c|c|c|c|c|c|c|c|c|c|c|c|c|c|c|c|c|c|c|c|c|c|c|c|}
\hline \multirow[b]{3}{*}{ Diet... } & \multicolumn{6}{|c|}{ Standard chow $(n 9)$} & \multicolumn{6}{|c|}{ Chow + beef suet $(n 10)$} & \multicolumn{6}{|c|}{ Chow + sunflower oil $(n 9)$} & \multicolumn{6}{|c|}{ Chow + fish oil $(n 10)$} \\
\hline & \multicolumn{2}{|c|}{ Basal } & \multicolumn{2}{|c|}{$\begin{array}{c}10^{-7} \\
\text { M-NOR }\end{array}$} & \multicolumn{2}{|c|}{$\begin{array}{c}10^{-5} \\
\text { M-NOR }\end{array}$} & \multicolumn{2}{|c|}{ Basal } & \multicolumn{2}{|c|}{$\begin{array}{c}10^{-7} \\
\text { M-NOR }\end{array}$} & \multicolumn{2}{|c|}{$\begin{array}{c}10^{-5} \\
\text { M-NOR }\end{array}$} & \multicolumn{2}{|c|}{ Basal } & \multicolumn{2}{|c|}{$\begin{array}{c}10^{-7} \\
\text { M-NOR }\end{array}$} & \multicolumn{2}{|c|}{$\begin{array}{c}10^{-5} \\
\text { M-NOR }\end{array}$} & \multicolumn{2}{|c|}{ Basal } & \multicolumn{2}{|c|}{$\begin{array}{c}10^{-7} \\
\text { M-NOR }\end{array}$} & \multicolumn{2}{|c|}{$\begin{array}{c}10^{-5} \\
\text { M-NOR }\end{array}$} \\
\hline & Mean & SE & Mean & SE & Mean & SE & Mean & SE & Mean & SE & Mean & SE & Mean & SE & Mean & SE & Mean & SE & Mean & SE & Mean & SE & Mean & SE \\
\hline \multicolumn{25}{|c|}{ Stimulated popliteal depot } \\
\hline Perinodal & $4 \cdot 30$ & 0.06 & 4.64 & 0.09 & $5 \cdot 30$ & 0.06 & 4.01 & 0.05 & $4 \cdot 34$ & 0.06 & 4.88 & 0.05 & $4.64 \dagger$ & 0.03 & 4.83 & 0.03 & 5.28 & 0.03 & $3.91 \dagger$ & 0.02 & $4 \cdot 11 \dagger$ & 0.03 & $4.83 \dagger$ & 0.02 \\
\hline Middle & 4.23 & 0.08 & 4.52 & 0.08 & 5.00 & 0.05 & 3.88 & 0.06 & $4 \cdot 17$ & 0.08 & 4.79 & 0.03 & 4.51 & 0.04 & 4.75 & 0.02 & 4.97 & 0.03 & $3 \cdot 60^{*} \dagger$ & 0.07 & $3.93 \dagger$ & 0.06 & $4.73^{\star \star \star}$ & 0.02 \\
\hline Remote & 3.96 & 0.08 & 4.39 & 0.08 & 4.97 & $0 \cdot 10$ & $3.48 \dagger$ & 0.09 & 4.03 & 0.06 & 4.75 & 0.03 & $4 \cdot 12^{\star}$ & 0.08 & $4 \cdot 43^{\star \star \star}$ & 0.03 & 4.84 & 0.02 & $3.31 \dagger$ & 0.06 & $3.65 \dagger$ & 0.06 & 4.62 & 0.03 \\
\hline \multicolumn{25}{|c|}{ Unstimulated popliteal depot } \\
\hline Perinodal & $4 \cdot 12$ & 0.08 & 4.42 & 0.07 & $5 \cdot 15$ & 0.05 & 3.93 & 0.07 & $4 \cdot 15$ & 0.07 & $4 \cdot 80$ & 0.04 & 4.40 & 0.04 & 4.71 & 0.04 & $5 \cdot 12$ & 0.05 & $3.64 \dagger$ & 0.07 & $4.00 \dagger$ & 0.04 & $4.77 \dagger$ & 0.04 \\
\hline Middle & $3.44^{\star \star \star}$ & 0.05 & $3.94^{*}$ & 0.06 & $4.87^{*}$ & 0.02 & $3 \cdot 46^{\star \star \star}$ & 0.06 & 3.98 & 0.07 & $4.69^{\star}$ & 0.04 & 4.00 & 0.07 & 4.42 & 0.07 & 4.89 & 0.02 & 3.41 & 0.04 & 3.84 & 0.04 & 4.63 & 0.05 \\
\hline Remote & $3 \cdot 27$ & 0.07 & 3.66 & 0.09 & 4.84 & 0.08 & 3.16 & 0.03 & 3.62 & 0.07 & $4 \cdot 61$ & 0.05 & 3.38 & 0.06 & 3.89 & 0.09 & 4.77 & 0.04 & 3.17 & 0.04 & 3.57 & 0.06 & 4.57 & 0.04 \\
\hline \multicolumn{25}{|l|}{ Mesenteric } \\
\hline Perinodal & $4 \cdot 10$ & 0.07 & 4.66 & 0.09 & $6 \cdot 24$ & 0.05 & $4.40 \dagger$ & 0.06 & $4.70 \dagger$ & 0.03 & $6 \cdot 12$ & 0.08 & 4.82 & 0.07 & $5 \cdot 10$ & 0.08 & 6.59 & $0 \cdot 10$ & $4 \cdot 28$ & 0.07 & 4.59 & 0.08 & $5 \cdot 82$ & 0.07 \\
\hline Remote & 3.51 & 0.04 & 3.92 & 0.08 & 5.55 & 0.07 & 3.64 & 0.03 & $4 \cdot 20$ & 0.04 & $5 \cdot 50$ & 0.03 & 3.67 & 0.04 & 4.33 & 0.09 & 5.52 & 0.05 & 3.54 & 0.03 & 4.04 & 0.06 & 5.41 & 0.06 \\
\hline \multicolumn{25}{|l|}{ Omental } \\
\hline Milky spots & $4 \cdot 36$ & 0.05 & 4.83 & 0.14 & 5.56 & $0 \cdot 10$ & 4.33 & 0.03 & 4.58 & 0.04 & $5 \cdot 33$ & 0.05 & 4.80 & 0.09 & $5 \cdot 15$ & 0.08 & 5.68 & 0.05 & 4.40 & 0.07 & 4.76 & 0.08 & $5 \cdot 34$ & 0.05 \\
\hline Remote & $3 \cdot 60$ & 0.05 & 4.04 & $0 \cdot 10$ & $5 \cdot 32$ & 0.07 & 3.62 & 0.02 & $4 \cdot 24$ & 0.04 & $5 \cdot 26$ & 0.04 & 3.67 & 0.08 & $4 \cdot 25$ & 0.06 & $5 \cdot 39$ & 0.05 & 3.54 & 0.03 & 4.09 & 0.05 & $5 \cdot 10$ & 0.05 \\
\hline Perirenal & 3.84 & 0.04 & 4.04 & 0.07 & 4.35 & 0.06 & 3.76 & 0.02 & 4.06 & 0.05 & $4 \cdot 26$ & 0.03 & 4.04 & 0.05 & $4 \cdot 26$ & 0.03 & 4.41 & 0.03 & 3.79 & 0.04 & 4.04 & 0.04 & $4 \cdot 28$ & 0.04 \\
\hline
\end{tabular}

Mean values were significantly different from the contiguous sample above it in the Table ${ }^{\star} P<0.05,{ }^{\star \star \star} P<0.001$ ( $t$ test).

年

‡Guinea pigs were fed on standard or lipid-enriched chow for 6 weeks before the start of immune stimulation (for details of diets and procedures, see p. 376 ); all ate standard unmodified chow during the $4 \mathrm{~d}$ of immune stimulation with lipopolysaccharide and were fasted for $18 \mathrm{~h}$ before killing. 
Table 4. Summary of effects of the experimental diets on lipolysis in the eleven samples of adipocytes stimulated in vivo by immune activation and by noradrenaline (NOR) in vitro ${ }^{*}$

\begin{tabular}{|c|c|c|c|c|c|c|c|c|}
\hline & \multicolumn{2}{|c|}{$\begin{array}{l}\text { No NOR (i.e. } \\
\text { basal lipolysis) }\end{array}$} & \multicolumn{2}{|c|}{$10^{-7} \mathrm{M}-\mathrm{NOR}$} & \multicolumn{2}{|c|}{$10^{-5} \mathrm{M}-\mathrm{NOR}$} & \multicolumn{2}{|c|}{$\begin{array}{c}10^{-7} \text { M-NOR } \\
\text { (\% basal) }\end{array}$} \\
\hline & $F$ & $P$ & $F$ & $P$ & $F$ & $P$ & $F$ & $P$ \\
\hline \multicolumn{9}{|l|}{ Stimulated popliteal } \\
\hline Perinodal & $61 \cdot 4$ & $<0.001$ & $32 \cdot 3$ & $<0.001$ & $32 \cdot 8$ & $<0.001$ & $18 \cdot 4$ & $<0.001$ \\
\hline Middle & $40 \cdot 2$ & $<0.001$ & $31 \cdot 7$ & $<0.001$ & $15 \cdot 3$ & $<0.001$ & $27 \cdot 1$ & $<0.001$ \\
\hline Remote & $24 \cdot 6$ & $<0.001$ & $36 \cdot 4$ & $<0.001$ & $7 \cdot 6$ & $<0.001$ & $16 \cdot 5$ & $<0.001$ \\
\hline \multicolumn{9}{|l|}{ Unstimulated popliteal } \\
\hline Perinodal & $25 \cdot 1$ & $<0.001$ & $24 \cdot 4$ & $<0.001$ & $17 \cdot 3$ & $<0.001$ & $9 \cdot 1$ & $<0.001$ \\
\hline Middle & $20 \cdot 7$ & $<0.001$ & $17 \cdot 3$ & $<0.001$ & $13 \cdot 2$ & $<0.001$ & 11.5 & $<0.001$ \\
\hline Remote & $4 \cdot 1$ & $<0.05$ & 3.5 & $<0.05$ & $5 \cdot 7$ & $<0.01$ & $2 \cdot 4$ & NS \\
\hline \multicolumn{9}{|l|}{ Mesenteric } \\
\hline Perinodal & $18 \cdot 5$ & $<0.001$ & $9 \cdot 5$ & $<0.001$ & $17 \cdot 3$ & $<0.001$ & $10 \cdot 9$ & $<0.001$ \\
\hline Remote & 5.6 & $<0.01$ & $6 \cdot 5$ & $<0.01$ & 1.31 & NS & $2 \cdot 8$ & NS \\
\hline \multicolumn{9}{|l|}{ Omental } \\
\hline Milky spots & $7 \cdot 1$ & $<0.01$ & $7 \cdot 2$ & $<0.01$ & $7 \cdot 1$ & $<0.01$ & 3.9 & $<0.05$ \\
\hline Remote & 1.5 & NS & $2 \cdot 3$ & NS & $5 \cdot 9$ & $<0.01$ & 0.8 & NS \\
\hline Perirenal (no lymph nodes) & $10 \cdot 6$ & $<0.001$ & $5 \cdot 00$ & $<0.01$ & $2 \cdot 7$ & NS & $2 \cdot 4$ & NS \\
\hline
\end{tabular}

${ }^{*}$ For details of diets and procedures, see Table 1 and p. 376.

†Values for Fisher's $F$ test were computed by ANOVA by dietary group.

Pond, 1997), we also found that guinea pigs do not fatten when fed additional lipid; the contrast may be a species difference, perhaps arising from the fact that sedentary adult guinea pigs on standard chow are about $150 \mathrm{~g}$ dissectible adipose tissue $/ \mathrm{kg}$ (Pond et al. 1984), fatter than normal laboratory rats. The constancy of final body mass in all experimental groups (Table 2) eliminates obesity or changes in total body composition as the cause of the effects described in Tables 3 and 4.

The differences between dietary groups in the swelling of the lymph nodes (Table 2) must arise from persistent metabolic or structural changes induced by the diets, possibly alterations to the fatty acid composition of membrane phospholipids, since at the time of immune stimulation all the animals were eating the same standard chow. The larger size of the right (non-stimulated) POP lymph node in animals that had eaten either of the diets rich in polyunsaturated fatty acids was not expected: feeding fish oil to mice for 5 weeks diminishes, while sunflower oil enhances the inflammatory response to LPS (Sadeghi et al. 1999). Swelling of the rat POP lymph node in response to grafting of foreign tissue was reduced by feeding fish oil compared with other diets supplemented with $n-6$ polyunsaturates or monounsaturated fatty acids (Sanderson et al. 1995), apparently because it curtails lymphocyte activation and proliferation.

\section{The response of adipose tissue to prolonged immune stimulation}

Maximum rates of lipolysis in the perirenal depot and in the 'remote' samples from the other depots studied are similar for all dietary groups to those reported by Pond \& Mattacks (1991). The site-specific rates of lipolysis in adipocytes from the node-containing depots after administration of LPS for $4 \mathrm{~d}$ (Table 3) were very similar to those found after only $24 \mathrm{~h}$ of LPS-stimulation of guinea pigs fed on standard chow (Pond \& Mattacks, 2002). The activation of perinodal adipocytes is thus concentrated into the early stages of the immune response, which is consistent with the hypothesis (Pond, 1999, 2001) that the role of these specialized adipocytes is to provision the proliferation and maturation of lymphoid cells. The higher rates of basal lipolysis in the perinodal samples than in the remote from node and the perirenal represent the sum of that induced by the endocrine conditions of fasting and by stimulation of the immune system (Pond \& Mattacks, 2002). During immunological quiescence, perinodal adipocytes release less glycerol than those not associated with lymph nodes (Mattacks \& Pond, 1999).

As previously reported (Pond \& Mattacks, 2002), the time courses of activation of lipolysis in mesenteric and POP adipocytes and their maximum responses are different. Even prolonged immune stimulation over $4 \mathrm{~d}$ failed to induce high rates of lipolysis in the 'remote' samples from the mesentery or omentum. Under normal conditions, these adipocytes may not be involved in local inflammation, though they may become so in certain pathological states (Pond, 2001).

\section{The effects of diet}

The pro-inflammatory diet of sunflower oil raised maximum lipolysis in the perinodal adipocytes, and promoted the spread of immune-stimulated lipolysis within and between node-containing depots (Table 3). The fish oil and suet diets did the opposite, although the swelling of the lymph nodes in response to the immune stimuli was similar following all the diets studied (Table 2). These effects on adipocytes may be secondary to the well established action of dietary lipids on the response of the lymph node lymphoid cells to the inflammatory stimuli (Yaqoob et al. 1994; Sanderson et al. 1995, 1997). The responses to the suet-enriched chow are consistent with previous reports of this diet reducing the interactions between lymphoid cells and explants of perinodal adipose tissue 
in vitro (Mattacks \& Pond, 1997), and the expression of receptors to tumour necrosis factor $\alpha$ on the perinodal adipocytes following LPS-stimulated immune responses. The manifestation of tumour necrosis factor $\alpha$ receptor type 1 on POP adipocytes is delayed and attenuated in rats fed on suet-enriched chow compared with controls fed on standard chow, but no change in receptor expression following a similar period on a diet enriched with sunflower oil could be detected (MacQueen et al. 2000).

The effects of the experimental diets on NOR-stimulated lipolysis in adipocytes from within $5 \mathrm{~mm}$ of lymph nodes (i.e. perinodal and middle samples) were not anticipated from previous studies (Mersmann et al. 1992, 1995) on the action of dietary lipids on the adrenergic receptors of adipocytes themselves. Recent discoveries about the relationship between membrane structure and its capacity to support receptors and secretion vesicles (Simons \& Ikonen, 1997) suggest that substitution of fatty acids in membrane phospholipids may underlie the effects reported here. Another possibility is a direct action of fatty acids on the production and manifestation of receptors (Grimaldi, 1999). However, such mechanisms should affect all adrenergically-controlled adipocytes about equally, but we found major effects of dietary lipids on NOR-stimulated lipolysis per se only in adipocytes that are known to be sensitive to local lymphoid secretions (Table 4).

These site-specific differences suggest a more complicated mechanism, involving diet-induced changes in the adjacent lymphoid cells rather than just on the adipocytes themselves. Calder (2001) and Wallace et al. (2000) have described various effects of dietary lipids on the secretions of lymphoid cells in response to immune stimulation. The lymph vessels divide into many fine branches within a few millimetres of major lymph nodes (Heath \& Brandon, 1983), an arrangement that would bring mobilized lymphoid cells into close proximity with the perinodal adipocytes, and enable them to take up fatty acids and signal molecules (Pond, 1996). The intracellular pathways of adrenergically-stimulated lipolysis are distinct from those of cytokine-mediated lipolysis (Londos et al. 1999), so may be independently modulated by the diet. The similarity in the effects of the suet and fish oil diets in all samples studied (Table 3), in spite of large differences in their fatty acid composition (Table 1), is also consistent with the interpretation that the primary effects are on the interaction between lymphoid cells and adjacent adipocytes.

Certain fatty acids are substrates for the prostanoid pathway in lymphoid cells, and act directly on transcription factors and genes (Grimble, 1998; Jump \& Clarke, 1999). The high flux of fatty acids into and out of adipocytes is probably why most of their genes are refractory to longterm regulatory control by fatty acids (Bernlohr et al. 1997). This role may be among the reasons for the higher proportion of polyunsaturated fatty acids and fewer saturated fatty acids in the triacylglycerols of perinodal adipocytes (Mattacks \& Pond, 1997). This gradient in the composition of storage lipid persists in guinea pigs fed for several weeks on a suet-enriched diet, but the absolute amounts of polyunsaturated fatty acids in the perinodal adipocytes fall, and interactions in vitro with lymphoid cells are impaired (Mattacks \& Pond, 1997).
According to the hypothesis that the adipose tissue around lymph nodes interacts in vivo with adjacent lymphoid tissue (Pond \& Mattacks, 1995, 1998, 2002; Mattacks \& Pond, 1999), the effects described here would contribute to the known actions of dietary lipids on immune function summarised by Calder (2001). The contrasting action of sunflower and fish oils parallels Guthrie \& Carroll's (1999) conclusion that $n-6$ fatty acids promote the development of mammary, colonic and pancreatic cancer, while large quantities of $n-3$ fatty acids suppress it. The capacity of sunflower oil to amplify the response of adipose tissue to immune stimuli may be among the ways in which diets rich in $n-6$ fatty acids promote atopic disease in children (Calder \& Miles, 2000) and hyperinsulinaemia, obesity, atherosclerosis and some forms of cancer in adults (Yam et al. 1996).

We conclude that the fatty acid composition of the diet before an immune response is elicited determines the extent of involvement of adipose tissue in node-containing depots. Fish oil attenuates, and sunflower oil enhances, the spread of increased lipolysis within the locally-activated POP adipose tissue, and from this depot to other lymphoid tissue-containing depots. Both paracrine interactions with the lymphoid cells (mediated by cytokines and/or eicosanoids) and the adrenergic pathway are modulated by dietary lipids. These site-specific differences in the control of short-term activation of adipose tissue may contribute to the long-term changes in its distribution that are associated with chronic immune disturbance (Pond, 2001).

\section{Acknowledgements}

We thank Dr Willem vas Dias, Seven Seas Ltd, Marfleet, Hull HU9 5NJ, UK, for the gift of fish oil for the guinea pigs' diet. We thank Drs Dick Colby and John Priddle for comments on the manuscript.

\section{References}

Berkowitz DE, Brown D, Lee KM, Emala C, Palmer D, An Y \& Breslow M (1998) Endotoxin-induced alteration in the expression of leptin and $\beta_{3}$-adrenergic receptor in adipose tissue. American Journal of Physiology 274, E992-E997.

Bernlohr DA, Coe NR, Simpson MA \& Hertzel AV (1997) Regulation of gene expression in adipose cells by polyunsaturated fatty acids. Advances in Experimental Medicine and Biology 422, 145-156.

Björntorp P (1996) Growth hormone treatment of hypophysectomized rats increases catecholamine-induced lipolysis and the number of $\beta$-adrenergic receptors in adipocytes - no differences in the effects of growth hormone on different fat depots. Obesity Research 4, 471-478.

Calder PC (2001) The effect of dietary fatty acids on the immune response and susceptibility to infection. In Nutrition, Immunity, and Infection in Infants and Children, pp. 137-172 [RM Suskind and K Tontisirin, editors]. Philadelphia, PA: Lippincott, Williams and Wilkins.

Calder PC \& Miles EA (2000) Fatty acids and atopic disease. Pediatric Allergy and Immunology 11, Suppl. 13, 29-36.

Cinti S (2001) The adipose organ: morphological perspectives of adipose tissues. Proceedings of the Nutrition Society 60, 319-328.

Colby RH \& Pond CM (1993) Site-specific differences in the 
responses of guinea-pig adipose tissue to changes in the fatty acid composition of the diet. Nutrition Research 13, 1203-1212.

Coppack SW (2001) Pro-inflammatory cytokines and adipose tissue. Proceedings of the Nutrition Society 60, 349-356.

El Hadri K, Courtalon A, Gauthereau X, Chambaut-Guérin AM, Pairault J \& Fève B (1997) Differential regulation by tumor necrosis factor- $\alpha$ of $\beta_{1^{-}} \beta_{2^{-}}$, and $\beta_{3^{-}}$-adrenoreceptor gene expression in 3T3-F442A adipocytes. Journal of Biological Chemistry 272, 24514-24521.

Grimaldi PA (1999) Roles of lipid-activated receptors in the adipogenic action of fatty acids. Lipids 34, S205-S208.

Grimble RF (1998) Nutritional modulation of cytokine biology. Nutrition 14, 634-640.

Guthrie N \& Carroll KK (1999) Specific versus non-specific effects of dietary fat on carcinogenesis. Progress in Lipid Research 38, 261-271.

Harris RBS, Zhou J, Youngblood BD, Rybkin II, Smagin GN \& Ryan DH (1998) Effect of repeated stress on body weight and body composition of rats fed low- and high-fat diets. American Journal of Physiology 275, R1928-R1938.

Heath T \& Brandon R (1983) Lymphatic and blood vessels of the popliteal node in sheep. Anatomical Record 207, 461-472.

Hwang D (2000) Fatty acids and immune responses - A new perspective in searching for clues to mechanism. Annual Review of Nutrition 20, 431-456.

Jump DB \& Clarke SD (1999) Regulation of gene expression by dietary fat. Annual Review of Nutrition 19, 63-90.

Langhans W (2000) Anorexia of infection: Current prospects. Nutrition 16, 996-1005.

Londos C, Brasaemle DL, Schultz CJ, Adler-Wailes DC, Levin DM, Kimmel AR \& Rondinone CM (1999) On the control of lipolysis in adipocytes. Annals of the New York Academy of Sciences 892, 155-168.

MacQueen HA, Sadler D \& Mattacks CA (2000) Dietary fatty acids influence the appearance of tumour necrosis factor- $\alpha$ receptors on adipocytes following an immune challenge. British Journal of Nutrition 84, 387-392.

Maestroni GJM (2000) Dendritic cell migration controlled by $\alpha 1 \beta$-adrenergic receptors. Journal of Immunology $\mathbf{1 6 5}$, 6743-6747.

Mattacks CA \& Pond CM (1997) The effects of feeding suetenriched chow on site-specific differences in the composition of triacylglycerol fatty acids in adipose tissue and its interactions in vitro with lymphoid cells. British Journal of Nutrition 77, 621-643.

Mattacks CA \& Pond CM (1999) Interactions of noradrenalin and tumour necrosis factor- $\alpha$, interleukin- 4 and interleukin- 6 in the control of lipolysis from adipocytes around lymph nodes. Cytokine 11, 334-346.

Mersmann HJ, McNeel RL, Akanbi KA, Shparber A \& Hachey DL (1995) Influence of dietary fat on $\beta$-adrenergic receptors and receptor-controlled metabolic function in porcine adipocytes. Journal of Nutritional Biochemistry 6, 302-309.

Mersmann HJ, McNeel RL, Morkeberg JC, Shparber A \& Hachey DL (1992) $\beta$-Adrenergic receptor mediated functions in porcine adipose tissue are not affected differently by saturated vs unsaturated dietary fats. Journal of Nutrition 122, 1952-1959.

Moussa M, Tkaczuk J, Ragab J, Garcia J, Abbal M, Ohayon E, Ghisolfi J \& Thouvenot J-P (2000) Relationship between the fatty acid composition of rat lymphocytes and immune functions. British Journal of Nutrition 83, 327-333.

Orban Z, Remaley AT, Sampson M, Trajanoski Z \& Chrousos GP (1999) The differential effect of food intake and $\beta$-adrenergic stimulation on adipose-derived hormones and cytokines in man. Journal of Clinical Endocrinology and Metabolism 84, $2126-2133$
Pond CM (1996) Interactions between adipose tissue and the immune system. Proceedings of the Nutrition Society 55, $111-126$.

Pond CM (1999) Physiological specialisation of adipose tissue. Progress in Lipid Research 38, 225-248.

Pond CM (2001) Long-term changes in adipose tissue in human disease. Proceedings of the Nutrition Society 60, 365-374.

Pond CM \& Mattacks CA (1991) The effects of noradrenaline and insulin on lipolysis in adipocytes isolated from nine different adipose depots of guinea-pigs. International Journal of Obesity 15, 609-618.

Pond CM \& Mattacks CA (1995) Interactions between adipose tissue around lymph nodes and lymphoid cells in vitro. Journal of Lipid Research 36, 2219-2231.

Pond CM \& Mattacks CA (1998) In vivo evidence for the involvement of the adipose tissue surrounding lymph nodes in immune responses. Immunology Letters 63, 159-167.

Pond CM \& Mattacks CA (2002) The activation of adipose tissue associated with lymph nodes during the early stages of an immune response. Cytokine 17 (In the Press).

Pond CM, Mattacks CA \& Sadler D (1984) The effects of food restriction and exercise on site-specific differences in adipocyte volume and adipose tissue cellularity. 1. Superficial and intraabdominal sites. British Journal of Nutrition 51, 415-424.

Pöschl JMB, Paul K, Leichsenring M, Han SR, Pfisterer M, Bremer HJ \& Linderkamp O (1999) Effects of dietary supplementation of saturated fatty acids and of $n-6$ or $n-3$ polyunsaturated fatty acids on plasma and red blood cell membrane phospholipids and deformability in weanling guinea pigs. Lipids 34, 467-473.

Rayner DV (2001) The sympathetic nervous system in white adipose tissue regulation. Proceedings of the Nutrition Society $\mathbf{6 0}$, 357-364.

Rogausch H, Del Rey A, Oertel J \& Besedovsky HO (1999) Norepinephrine stimulates lymphoid cell mobilization from the perfused rat spleen via $\beta$-adrenergic receptors. American Journal of Physiology 276, R724-R730.

Sadeghi S, Wallace FA \& Calder PC (1999) Dietary lipids modify the cytokine response to bacterial lipopolysaccharide in mice. Immunology 96, 404-410.

Sanderson P, Yaqoob P \& Calder PC (1995) Effects of dietary lipid manipulation on graft vs host and host vs graft responses in the rat. Cellular Immunology 164, 240-247.

Sanderson P, MacPherson GG, Jenkins CH \& Calder PC (1997) Dietary fish oil diminishes the antigen presentation activity of rat dendritic cells. Journal of Leukocyte Biology 62, 771-777.

Shimotsuma M, Shields JW, Simpson-Morgan MW, Sakuyama A, Shirasu M, Hagiwara A \& Takahashi T (1993) Morpho-physiological function and role of omental milky spots as omentumassociated lymphoid tissue (OALT) in the peritoneal cavity. Lymphology 26, 90-101.

Simons K \& Ikonen E (1997) Functional rafts in cell membranes. Nature 387, 569-572.

Wallace FA, Miles EA \& Calder PC (2000) Activation state alters the effect of dietary fatty acids on pro-inflammatory mediator production by murine macrophages. Cytokine 12, 1374-1379.

Wallace FA, Miles EA, Evans C, Stock TE, Yaqoob P \& Calder PC (2001) Dietary fatty acids influence the production of Th1-but not Th2-type cytokines. Journal of Leukocyte Biology 69, 449-457.

Yam D, Eliraz A \& Berry EM (1996) Diet and disease - The Israeli paradox: Possible dangers of a high omega-6 polyunsaturated fatty acid diet. Israel Journal of Medical Sciences 32 , $1134-1143$.

Yaqoob P, Newsholme EA \& Calder PC (1994) The effect of dietary lipid manipulation on rat lymphocyte subsets and proliferation. Immunology 82, 603-610. 